\title{
Modeling In-Flight Inert Gas Distribution in a 747 Center Wing Fuel Tank
}

\author{
William M. Cavage* \\ Federal Aviation Administration, Atlantic City, NJ 08405 \\ Timothy Bowman ${ }^{\dagger}$ \\ Boeing Phantom Works, St. Louis, MO 63166
}

\begin{abstract}
Extensive development and analysis has illustrated that fuel tank inerting, using air separation modules, is a reasonably cost-effective approach to preventing fuel tank explosions. To support the development of the Federal Aviation Administration inerting system, analytical and scale replica models of a Boeing 747 center wing fuel tank were developed and used to gage the ability of these relatively simple modeling methods to predict the ullage oxygen concentration of a specific fuel tank, given a flight cycle and inerting system performance. The analytical and scale models resulting average ullage oxygen concentration of the multiple bay fuel tank agreed well with measured flight test data, given the measured system performance and flight profile. Oxygen concentration distribution, in terms of the difference in oxygen concentration between the different bays of the test aircraft during the descent portion of the flight test, correlated well with the results obtained from both models, while model peak values deviated significantly from some of the measured flight test peak values. The resulting bay oxygen concentrations predicted by both models agreed with the flight test results within 1 percent oxygen on average, but the critical bay 1 (highest oxygen concentration bay) model values deviated by as much as 2 percent oxygen when compared with two separate tests. The computational model of a single flight test event illustrated fair agreement with the flight test data.
\end{abstract}

\section{Introduction}

\section{Background}

The Federal Aviation Administration (FAA) has placed significant emphasis on fuel tank safety since the TWA Flight 800 accident in July 1996. Extensive development and analysis has shown that fuel tank inerting is reasonably cost-effective if air separation modules (ASM), based on hollow-fiber membrane technology, are used in an effective manner to produce inert gas. To illustrate this, the FAA, with the assistance of several aviation-oriented companies, developed an onboard inert gas generation system (OBIGGS) with ASMs that uses aircraft bleed air to generate nitrogen-enriched air (NEA) at varying flow and purity during a commercial airplane flight cycle. The system was designed to fit in the pack bay area of a Boeing 747 and inert the center wing tank (CWT) of a type $100,-200$, or SP.

In support of this research, the William J. Hughes Technical Center Fire Safety Branch has developed two modeling methods to predict ullage oxygen concentration in compartmentalized fuel tanks, given a set of inerting conditions and a flight profile. Many commercial aircraft CWTs are made up of several bays, compartmentalized by the web/cell structures of the wing box. The analytical model, assumes perfect mixing, to calculate the mass of oxygen within the ullage space of a series of attached bays, at any time step, given a flight cycle and inerting system performance. The physical model employs a scale fuel tank replica in an altitude chamber, which can be inerted with a scaled flow from a small NEA generator, in the same manner as the full-scale aircraft. The ullage oxygen concentration of the scale tank can be measured at several locations to obtain the resulting full-scale ullage oxygen

\footnotetext{
* Project Manager, Fire Safety Research, Wm. J. Hughes Technical Center/Bld. 204, Senior Member AIAA

${ }^{\dagger}$ Senior Specialist Engineer, Aircraft Fuel System and Fire Protection Systems, PO Box 516, MC S111-1260
} 
concentration distribution. Additionally, a computational fluid dynamic model of the Boeing 747 CWT was developed by Boeing Phantom works and used to simulate inert gas distribution in the test aircraft during descent.

\section{Previous Research}

Previous fuel tank ullage modeling research was primarily performed by the United States Department of Defense to study the survivability of military aircraft. The most well known of these studies culminated in an extensive model of ullage gas composition, given a wide range of mission data, fuel data, and OBIGGS performance [1]. This model was validated with a wide range of test data generated in a ground test facility designed to simulate an aircraft fuel tank ullage during various military aircraft flight profiles. The focus of the modeling research was to study ullage flammability and air evolution from fuel during particular military missions, which included the effect of tank slosh and vibration.

Early FAA fuel tank modeling focused on quantifying the amount and purity of NEA needed to inert a rectangular aircraft fuel tank test article in support of FAA research on ground-based inerting. This research was complimented by the development of an analytical model to calculate the effect of adding NEA to an ullage, given a constant flow and purity (oxygen concentration) and assumed perfect mixing [2].

Additional modeling was performed to study the inerting of multiple-bay, compartmentalized fuel tanks using a scale 747 plywood model built and instrumented to allow for variable methods of depositing inert gas and venting ullage. This modeling validated that multiple-bay fuel tanks could be inerted in the same manner as single-bay rectangular tanks by distributing the inert gas throughout the tank fairly evenly. It also illustrated that by depositing all the inert gas in a single location, strategically away from the fuel tank vent system, a more simplistic deposit system could actually improve the efficiency of the inerting process, allowing for a lower average ullage oxygen concentration, given the same available quantity of inert gas [3]. The FAA also developed a multiple-bay analytical model of ground-based inerting, using the previously developed analytical model discussed in reference 2, to study the capabilities and limitations of that rudimentary method. Comparisons of both the scale 747 CWT replica and the multiple-bay analytical model data were made with full-scale ground inerting measurements and also with a computational fluid dynamics model developed by Boeing Phantom Works [4]. This reference illustrates the excellent agreement between ground inerting data on a 747SP ground test article and data obtained with the scale 747 plywood tank, as compared to the multiple-bay analytical model, and gives the results of a mock trade study to illustrate the usefulness of both FAA-developed modeling methods.

To support the development of the FAA OBIGGS, existing modeling techniques were applied to predict ullage oxygen concentration when given a flight cycle and OBIGGS performance. A plywood scale replica of an Airbus model A320 CWT was built, instrumented, and tested in an altitude chamber capable of simulating the conditions of a commercial transport flight. Additionally, an analytical model was developed that calculated the mass of oxygen within a generic fuel tank ullage of known volume during a commercial transport airplane flight cycle, given the quantity and purity of inert gas generated at each time step. These two modeling methods were compared to joint FAA and Airbus flight tests on an A320 operated by Airbus. The results of both models illustrated excellent agreement of the data trends with measured flight test data, while peak and resulting values had generally good agreement. Both modeling methods gave consistent results when given the same input data to make predictions [5].

\section{Test Articles}

\section{NASA 747 SCA}

Flight tests of the FAA inerting system were performed in cooperation with NASA on their 747 SCA, which is a highly modified Boeing 747 used to carry the Space Shuttle Orbiter, to study the OBIGGS performance throughout typical flight conditions and to validate existing inerting models. Figure 1 gives a cut-a-way view of the 747 fuel tank which is typical of all classic style 747 aircraft. The FAA OBIGGS was installed in the test aircraft pack bay area, and the inert gas from the system was deposited in bay 6 of the aircraft CWT. The primary instrumentation employed for the flight tests was the gas sample tubing in the CWT that allowed continuous oxygen concentration measurements at eight locations (see figure 2) using the FAA Onboard Oxygen Analysis System (OBOAS). The OBOAS is a specialized instrument that continuously measures the oxygen concentration in an aircraft ullage using conventional oxygen analyzers (galvanic cell), a powerful diaphragm pump, and a pressure-regulated sample train 
[6]. Additionally, OBIGGS NEA flow and purity were measured to analyze the system performance. Atmospheric pressure was also measured during the flight tests [7].

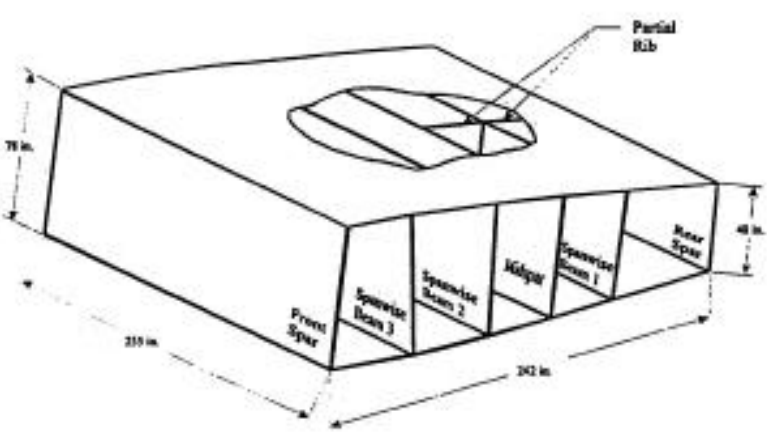

Figure 1. Boeing 747 CWT cut-a-way view.

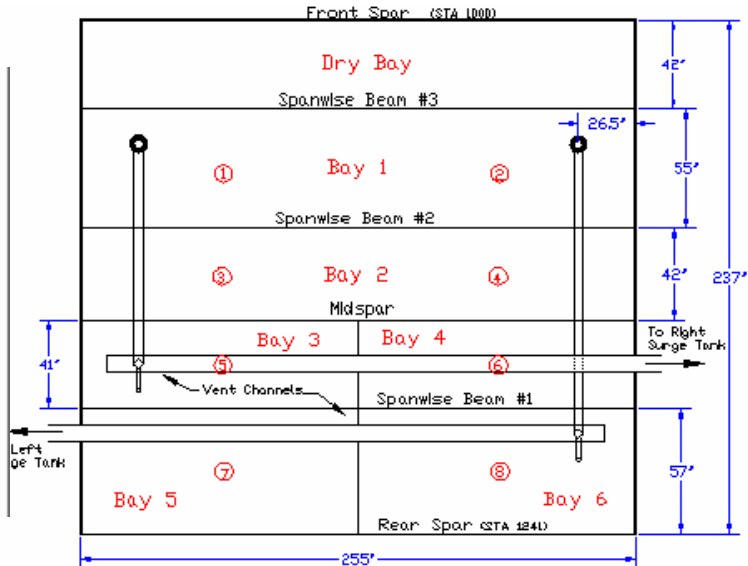

Figure 2. Top diagram of the Boeing 747 CWT.

\section{Boeing 747 Center Wing Tank Scale Model}

To model inert gas distribution in a multiple-bay fuel tank, the $24 \%$ length scale plywood 747 CWT discussed in reference 3 was tested in an environmental chamber and inerted with a scaled system performance (flow) from a previously performed flight profile. The tank has a removable lid to change the deposit, venting, or instrumentation configuration of the tank. NEA was made from bottled nitrogen and shop air using a mixer attached to an oxygen analyzer and dispensed to the tank with a mass flow controller. The environmental chamber can simulate the temperature and pressure environment of a commercial transport airplane. The altitude profile was controlled by an operator who varied air entering the chamber while the vacuum pump

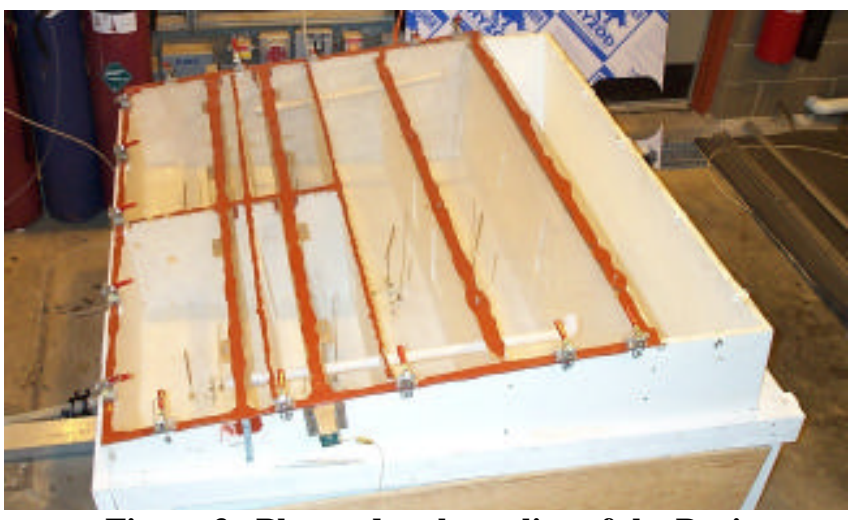

Figure 3. Plywood scale replica of the Boeing 747 CWT. continuously operated. The oxygen concentration was continuously measured at eight locations, similar to the eight flight test gas sample locations given in figure 2, using the OBOAS. All data was recorded with a data acquisition system and stored on a computer.

\section{Analytical Model}

To better understand the effect of some flight and system performance scenarios on the inerting process, an analytical model was developed to calculate tank ullage oxygen concentration in several connected bays of a fuel tank, given the specific tank bay volumes, starting oxygen concentration, and inerting system performance schedule. The performance schedule gives a mission time and altitude with the OBIGGS volume flow rate and purity (oxygen concentration). The tank ullage temperature is also included, and the model assumes the pressure inside the tank is equal to ambient pressure outside the aircraft. This calculation is first explained for a simple, cascading inerting model of $n$ bays that receives inert gas in bay 1 and vents the mixed ullage out of the nth bay to atmospheric pressure P. Figure 4 illustrates the concept. The application of this precise calculation to the six-bay 747 CWT will then be discussed. Additionally, a computational fluid dynamics model was developed using FLUENT ${ }^{\mathrm{TM}}$, which determined the oxygen concentration distribution in a 747 CWT model, given a set of input conditions. 


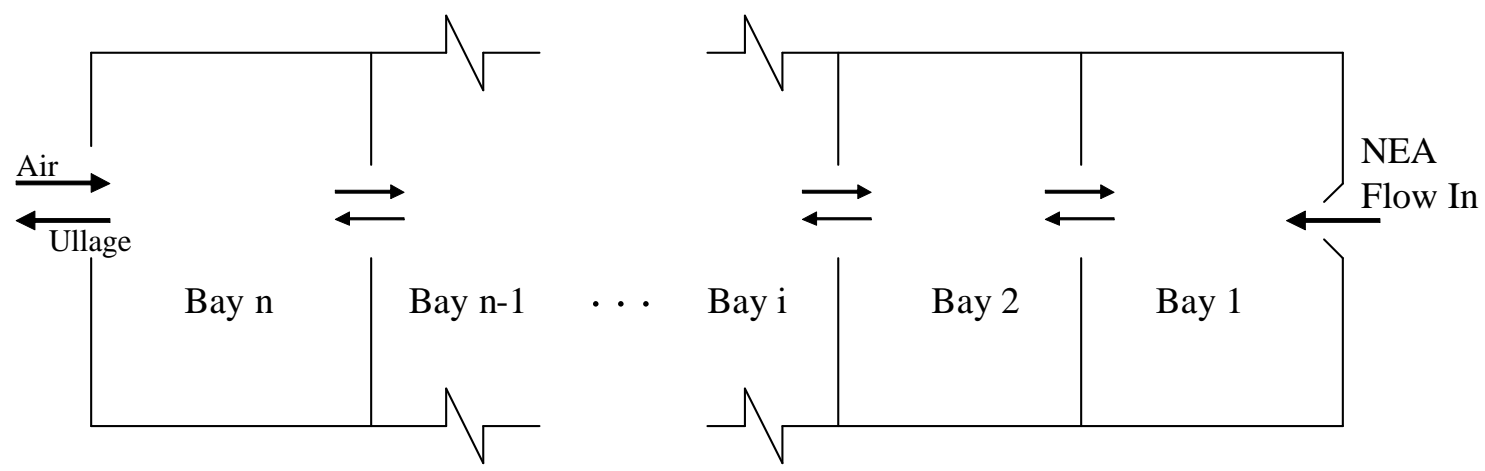

Figure 4. Diagram of cascading inerting tank with $\mathbf{n}$ bays.

\section{Calculation of Cascading Inerting}

To calculate the oxygen concentration in each bay for the cascading inerting case illustrated in figure 4, the NEA volume flow and purity was first converted at each time step to a mass of oxygen deposited in the tank based on the ullage density, given the altitude (pressure $P$ ) and ullage temperature $(T)$, and the universal gas constant for air $(R)$.

$$
\rho_{u}=P / R T_{u}
$$

These calculations were performed at individual time steps $t$ with $\Delta t$ being the difference in time between time $t$ and $t-1$. Due to changing atmospheric pressure, the density of the ullage changes between time steps.

$$
\Delta \rho=\rho_{u_{t}}-\rho_{u_{t-1}}
$$

Given the volumetric inert gas flow rate $\mathrm{Q}_{\mathrm{NEA}}$ and the inert gas oxygen concentration $F o_{\mathrm{NEA}}$, the mass of NEA $\left(\mathrm{M}_{\mathrm{NEA}}\right)$ and the mass of oxygen in the NEA $\left(M o_{\mathrm{NEA}}\right)$ was calculated using the following equations.

$$
\begin{aligned}
& M_{N E A}=Q_{N E A} \rho_{u} \Delta t \\
& M o_{N E A}=M_{N E A} F o_{N E A}
\end{aligned}
$$

The calculation determines the mass of oxygen in each bay at the start of the mission, given the individual bay volumes and starting oxygen concentration in each bay, and tracks the change in mass of oxygen due to the addition of inert gas, the passing of mixed ullage gas from bay to bay, and ventilation of ullage gas from the tank. The mass of ullage gas in each bay $(M)$ and the mass of oxygen in each bay $(M o)$ are tracked at each time step using the following general equations with the indices $i$ referring to the bay number.

$$
\begin{gathered}
M_{\mathrm{B} a y i}(t)=M_{\mathrm{B} a y i}(t-1)+\Delta M_{\text {ullage }} \\
M o_{\mathrm{B} a y i}(t)=M o_{\mathrm{B} a y i}(t-1)+M o_{\mathrm{Out}_{\mathrm{B} a y i}(t)-M o_{\mathrm{Out}_{\mathrm{B} a y} i+1}(t)}
\end{gathered}
$$

These equations allow for the fraction of oxygen $(F o)$ of the ullage gas in each bay to be calculated using the following equation.

$$
F O_{\text {Bay } i}=M_{\text {Bay } i}(t) / M o_{\text {Bay } i}(t)
$$


In equations 5 and 6 , the amount and oxygen fraction of the ullage gas being passed from bay to bay is dependent upon the mass of NEA entering bay 1 and the change in atmospheric pressure, which determines the amount of air entering bay $\mathrm{n}$ if any. Since the calculation assumes no mass storage in the tank, the amount of NEA entering bay 1 is equal to the amount of ullage gas passed from bay to bay when atmospheric pressure is not changing. When the atmospheric pressure is decreasing due to increasing altitude, additional ullage mass, with associated oxygen, is also ventilated from bay $\mathrm{n}$. When the mass of NEA is greater than the mass of air trying to enter the tank, due to increasing atmospheric pressure, ullage gas passes from bay 1 to bay 2 and so on, until it is ventilated out of the tank at bay $\mathrm{n}$. When the mass of air trying to enter the tank overcomes the mass of NEA being deposited in bay 1, air enters the tank at bay $\mathrm{n}$ and ullage gas is passed from bay $\mathrm{n}$ to bay $\mathrm{n}-1$ and so on, as far into the tank as the mass flow warrants, given the successive volume total of the tank bays. Figure 5 illustrates the specific calculations made in each bay at each time step $(t)$, given the above stated methodology.

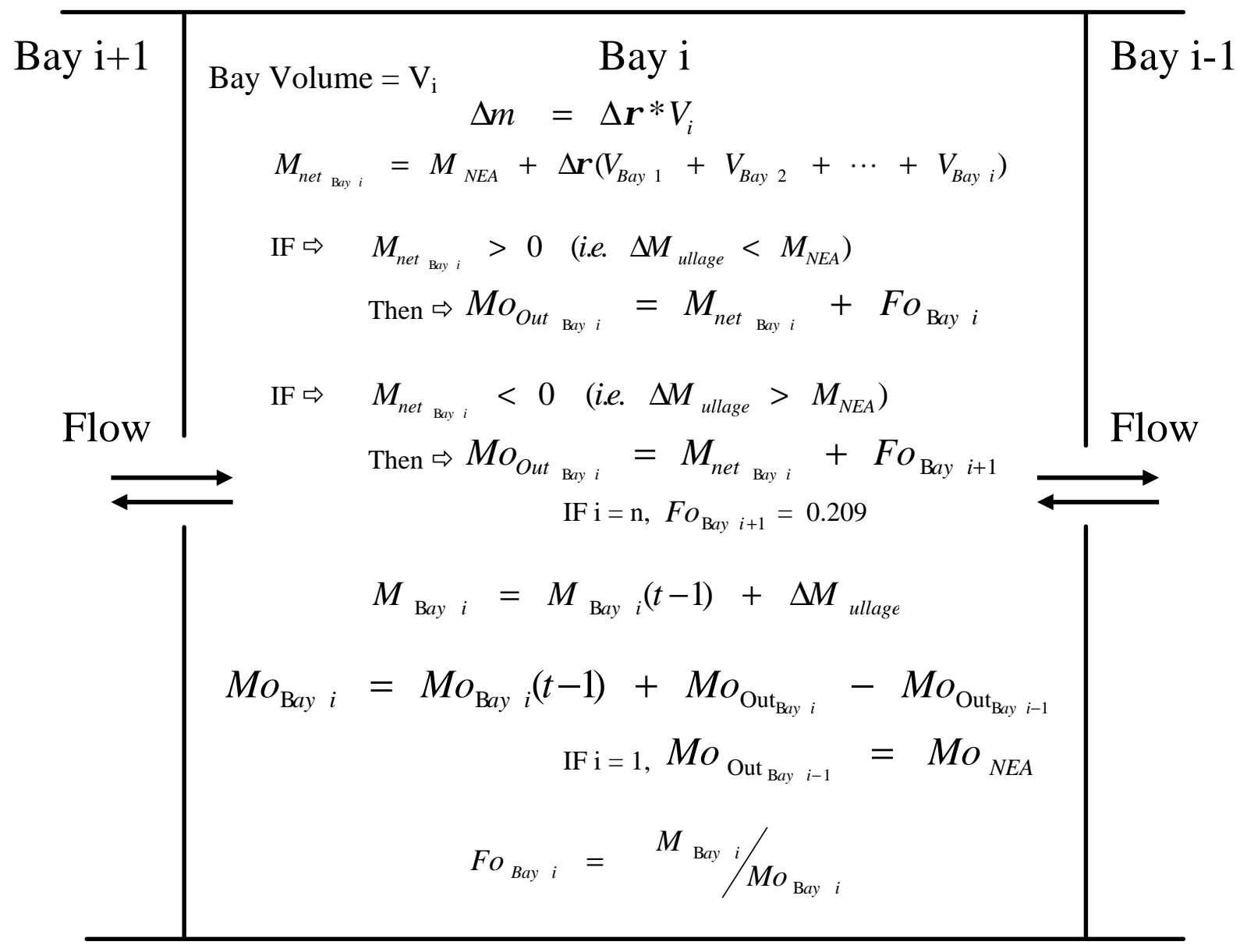

Figure 5. Statement of cascading inerting calculations in bay $i$ of a tank with $\mathbf{n}$ bays.

\section{Calculation of Multiple Bay Inerting}

To calculate the inert gas distribution in terms of oxygen concentration within the six-bay CWT of a Boeing 747, the simple relationships of gas passing from one bay to another, developed for the cascading inerting case, had to be modified to a more complex relationship with certain bays receiving ullage gas from several other bays and ullage gas being vented from and receiving air into two different bays. Figure 6 shows a diagram of the assumed flow pattern for the six-bay tank illustrated in figures 1 and 2. Note the bay number convention is the same as in figure 2 and is not consistent with the bay numbering convention given for the cascading inerting explanation from figure 4 .

To adapt the cascading model to the multiple-bay inerting model, first note that all NEA is deposited in bay 6 and vents out of both bays 1 and 3. The ullage gas displaced by the NEA deposited in bay 6 is split between bays 4 and 
5. The ullage gas displaced from bay 4 is split between bays 3 and 2. Bay 3 vents some displaced ullage out of the tank, while another portion is also deposited into bay 2. The model assumes everything flowing into bay 2 flows into bay 1 and everything that flows into bay 1 flows out of the vent. The flows were originally split using the ratios of flow areas separating the bays in question. Each bay has several openings between them to allow fuel, tubing, and ullage gas to pass freely between them. The area of vent system opening is used to scale the flow out of bay 3 . This, however, was not realistic for air entering the vent system, as it is the area difference between the vent in bay 1 and the vent in bay 3 that would tend to split the flow into the tank. A separate area ratio was used to split flow into the tank through the vent system based on the difference in crosssectional area of the vent tubing. Eventually all of the

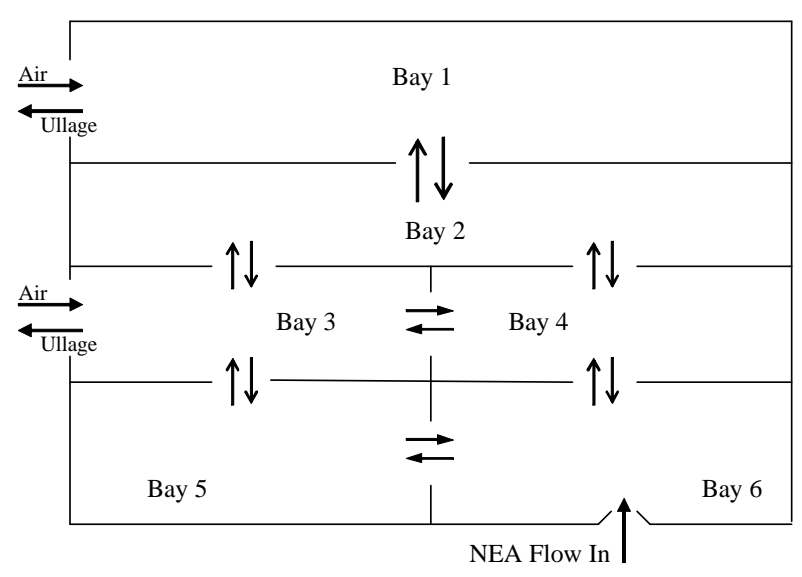

Figure 6. Analytical multiple bay inerting model assumed flow pattern. area ratios were modified to better match the measured oxygen concentration distribution of full-scale test data. The model assumes in all other bays besides bay 3 that in the case of air entering the tank due to descent, the flow reenters the bay in the same manner it left. The model also assumes that when air is entering the tank, bay 1 receives all input flow from the vent system.

\section{Computational Model}

To gauge the ability of complex analysis tools to accurately simulate oxygen concentration distribution during uneven inert gas deposit in a fuel tank with multiple compartments, a CFD model was developed with the analysis package FLUENT. This modeling tool has the ability to track fluid species (i.e oxygen, nitrogen) at given locations. The data was generated using the FLUENT CFD solver that uses a finite volume method where the general conservation (transport) equation, which includes mass, momentum, energy, diffusion, etc., is solved for each finite volume cell. The model was solved assuming turbulent flow throughout the tank so that the oxygen and nitrogen concentration is based on mixing and diffusion of the different gas species.. The developed wire frame model of the 747 CWT had approximately 500,000 cells and ran on a Linux Cluster in five days or 246 CPU hours of computational time using two CPUs. More detailed information on the tool is available on line to registered users.

\section{Results}

\section{Cascading Inerting Results}

To allow for mutual validation of both the integrity of the scale 747 tank and the cascading model methodology, the plywood CWT was modified to duplicate a four-bay cascading inerting case by changing the experimental configuration to deposit equally into bays 5 and 6 and to vent entirely from bay 1 , as described by the convention in figure 2. This makes bays 5 and 6 in the 747 scale tank bay 1 , as defined in figure 4 , and bay 1 from the scale tank bay $\mathrm{n}$ from the same figure, which is defined by the cascading inerting convention as bay 4 . The scale penetration holes between the bays were minimized to promote mixing and the vent system was modified to increase mixing in what is now called bay 4 for the discussion of cascading inerting. A flight profile and inert gas deposit schedule was developed, and both the scale tank and the analytical model were used to predict the inert gas distribution of this generic case. The measured flight profile and inert gas deposit values were used as input data for the analytical model to eliminate any human error in the data comparison.

Figure 7 compares the results of both modeling methods to assess their validity. The relatively simple calculation compares well with the experiment for the increasing altitude and stable cruise portion of the test, but agrees less during the descent phase of the demonstration. This is most likely due to small leaks in the scale tank that allow air to enter in places other than bay 4. The removable lid uses a gasket seal that becomes compressed and warn over time, creating small voids between the plywood and lid. This would explain the large deviation in bay 1 from figure 4 , as it is the area of the scale tank that is the most difficult to seal with the lid. Note that the bay numbering convention listed in figure 7 is given in figure 4 , with bay $n$ being bay 4 , and is not consistent with the illustrated bay numbering convention of the 747 fuel tank. 


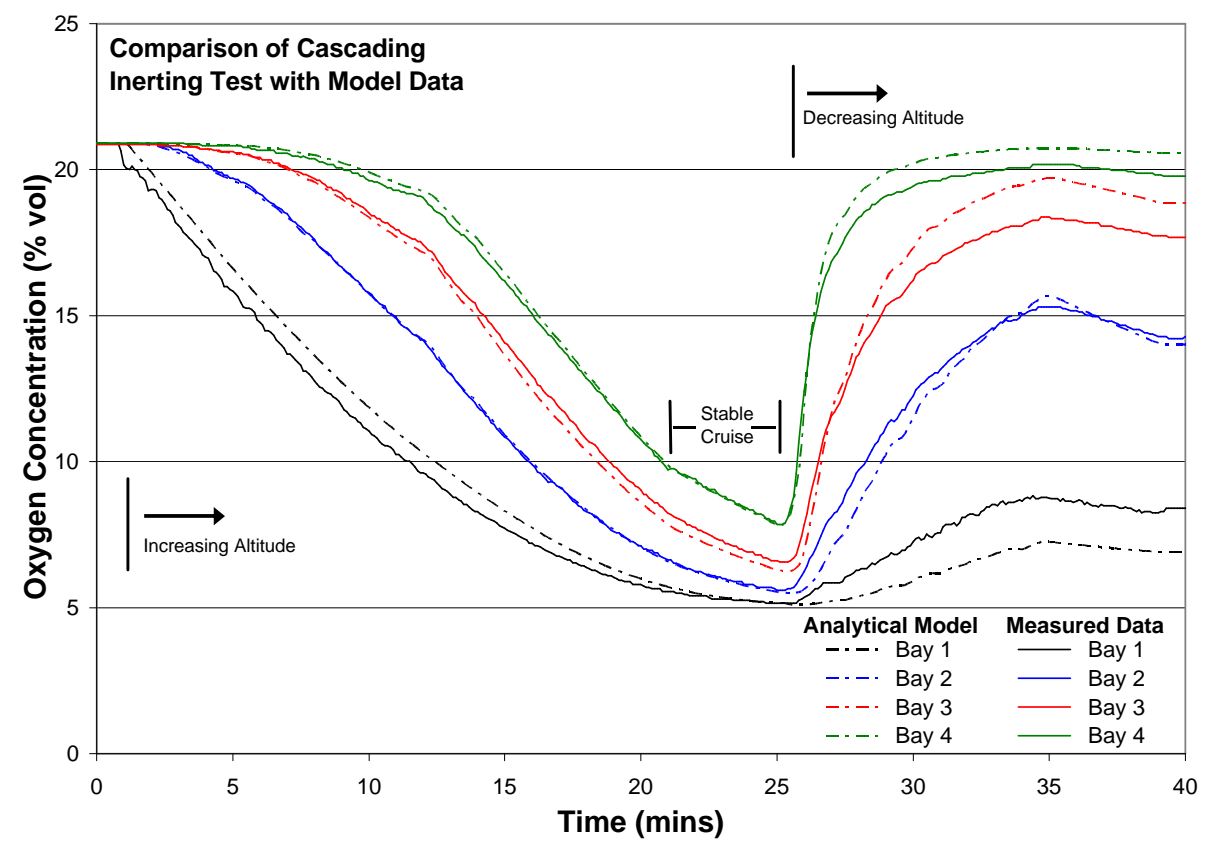

Figure 7. Comparison of bay oxygen concentration for the analytical model and the modified scale plywood 747 CWT for a cascading inerting flow scenario.

Figure 8 gives the weighted average oxygen concentration, based on bay volume, of the cascading inerting bay tank for both the analytical model and the measured data. These agree well, further enforcing the assumption that the measured deviations were from air leaking past the tank seal lid. Small leaks would have little or no effect on the overall average because it would not change the total mass of air deposited in the tank and would create only small changes in the efficiency of the inerting process. Figure 8 also gives the calculated ullage oxygen concentration of an equivalent single bay tank to illustrate the increase in the efficiency of the inerting process from the effect of cascading.

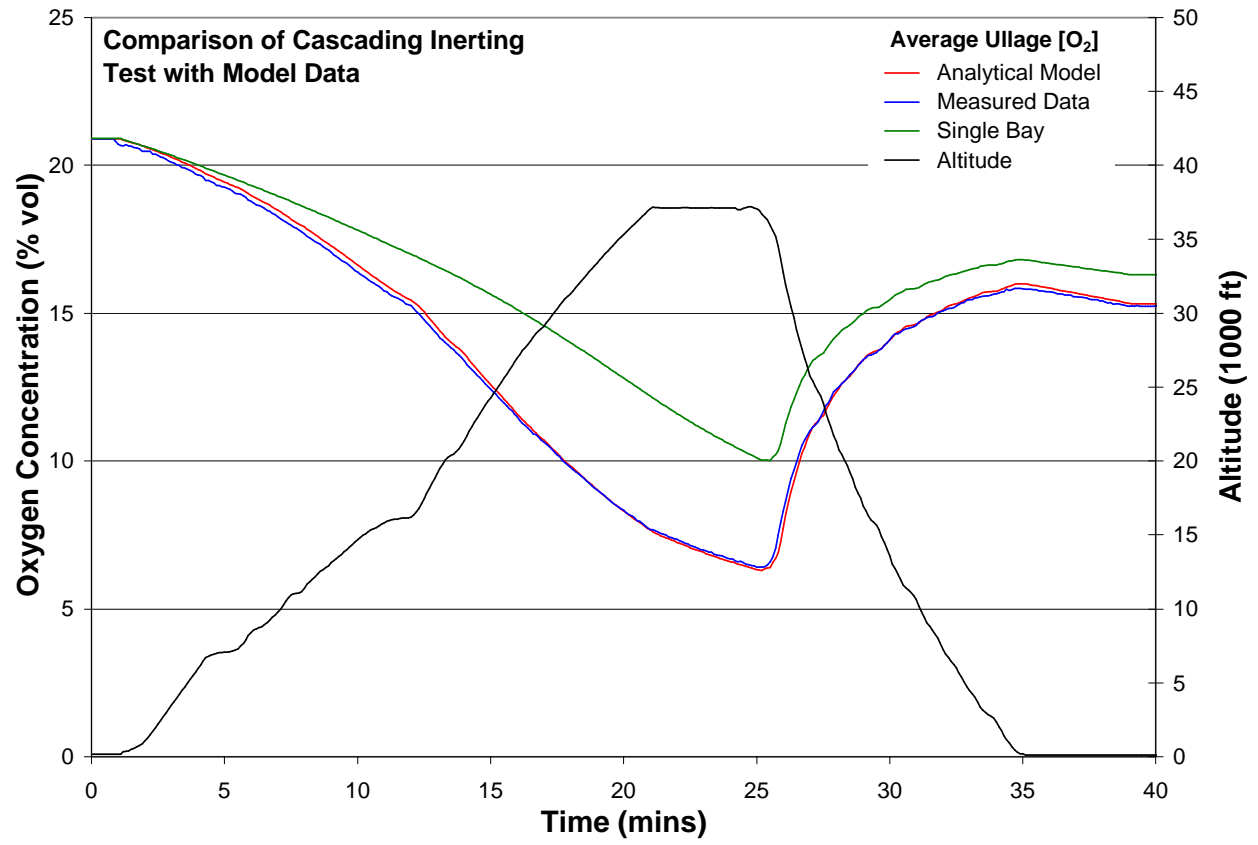

Figure 8. Comparison of average tank oxygen concentration for the analytical model and the modified scale plywood 747 CWT for a cascading inerting flow scenario.

7

American Institute of Aeronautics and Astronautics 


\section{Comparison of Flight Test Results With Modeling Methods}

It was apparent from reviewing ground inerting data from the NASA 747 SCA testing that the ratios of the flow splits in the analytical model allowed for relatively poor duplication of full-scale aircraft results. This was also true of the scale plywood tank, which was built with a relatively low fidelity (precise duplication of size, shape, and location), when considering the area through which flow passes from bay to bay and the vent system in general. This is contrary to previous results (ref 4) that illustrated fairly good agreement between both modeling methods and full-scale data during ground inerting events. These previous results required no modification of the plywood scale tank or changing of the flow split ratios inherent to the analytical model based on the cross-sectional flow area between the different bays. This is probably due to the different nature of the two ground inerting events. Previous ground inerting studies employed high flow rates with a single NEA purity (oxygen concentration), which may have made mixing within each bay more thorough and consistent. Also, previous ground inerting configurations had a simpler venting methodology that allowed for all flow entering a bay with a vent to exit that bay through the vent. Due to the different configuration of the NASA 747 SCA fuel tank, which is plumbed and vented for in-flight inerting, this simpler flow/venting methodology was not an option. Regardless, flight test ground inerting data was used to modify the existing holes between the different bays in the plywood scale replica. Additionally, this data was also to change the ratios at which flow out of some bays was split to the surrounding bays.

Figure 9 gives the measured bay oxygen concentration distribution of the NASA 747 SCA CWT compared to both the analytical model and the scale plywood tank during a ground inerting test. As both models were modified based on this data, the results compare well, although the limitations of both modeling methods can be seen. However, the deviation of both modeling methods from the results measured on the NASA 747 SCA in bay 6 indicate an irregularity in that measurement since the modeling results of this bay require only a simple analytical calculation, with no issues of flow splits or scale tank hole sizes, because all the NEA is deposited in bay 6. This probably indicates that the measurement of oxygen concentration in bay 6 was biased from the actual volume concentration of the entire bay. The measured flight test data from bay 6 consistently deviated from both modeling methods during all simulations when the oxygen concentration is decreasing in that bay.

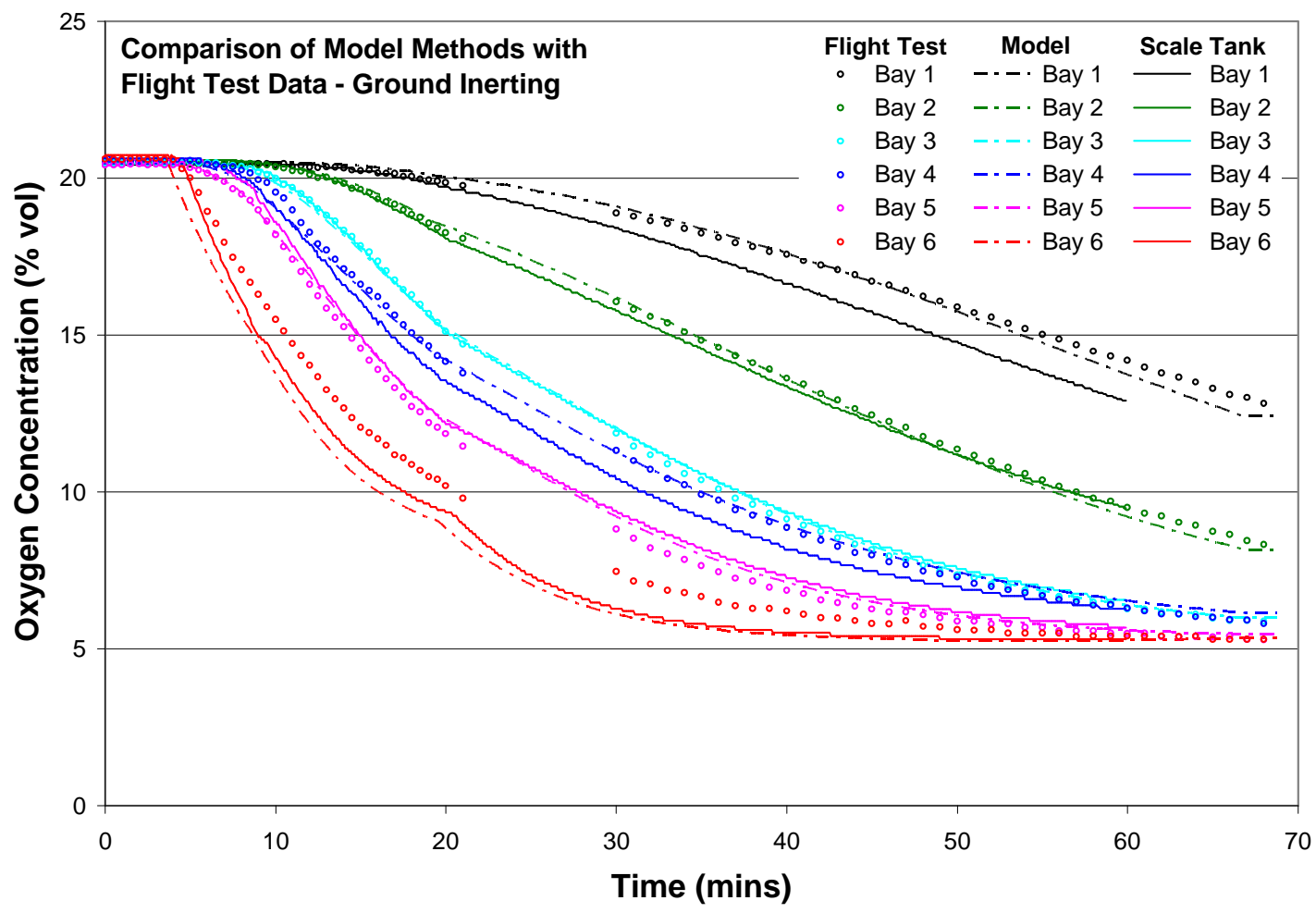

Figure 9. Comparison of bay oxygen concentration for the analytical model and the scale plywood 747 CWT with the NASA 747 SCA data for a ground inerting test. 
To conserve time and resources, the modeling work was focused on the duplication of measured flight test results during the descent portion of the flight cycle. The FAA OBIGGS inerting philosophy relies on obtaining a relatively low oxygen concentration within all areas of the CWT while the aircraft is at a stable cruise altitude. Since most commercial aircraft fuel tanks are vented to atmospheric pressure, when the aircraft descends, air will enter the ullage through the fuel tank vent system. At this point, the FAA OBIGGS switches to a high flow mode that provides a higher quantity of less pure (higher oxygen concentration) NEA to stave off air entering the ullage, aiming for an oxygen concentration after landing of less than 12 percent by volume on average. This dynamic inerting event is of most interest because it will be the main factor driving the size of the inerting system for a given aircraft fuel tank.

As was the case with the ground inerting comparison, it was apparent from preliminary modeling exercises that the flow split of the vent system depositing air into the tank ullage during descent for both modeling methods did not compare well with the measured flight test data. The data from the descent portion of a single test was used to modify the ratio at which air entered bays 1 and 3 during descent in the analytical model. This flight test data was also used to make a small modification to the vent system of the scale plywood CWT.

Figures 10 and 11 give the measured bay oxygen concentration distribution of the NASA 747 SCA CWT compared to both the analytical model and scale plywood tank during the descent portion of one flight test. Figure 10 compares bays 1,2 , and 3, and figure 11 compares bays 4,5 , and 6 . The trends of each bay oxygen concentration compare very well with some notable discrepancies between the magnitudes of the data. Each model method compares better for some bays than others, with the analytical model comparing better for bay 1, which would be critical data for an engineer designing an inerting system for this fuel tank. Due to an instrumentation failure, there is no oxygen concentration data for bay 4 during part of the descent. No noticeable trend exists to describe the deviations of either model from the flight test data, although, for bays 1, 2, and 3, the analytical model and scale tank results tend to bracket the flight test results by about \pm 1 percent oxygen. The analytical model and scale tank results from bay 1 deviate from the flight test data by +0.8 and -1.1 percent oxygen respectively.

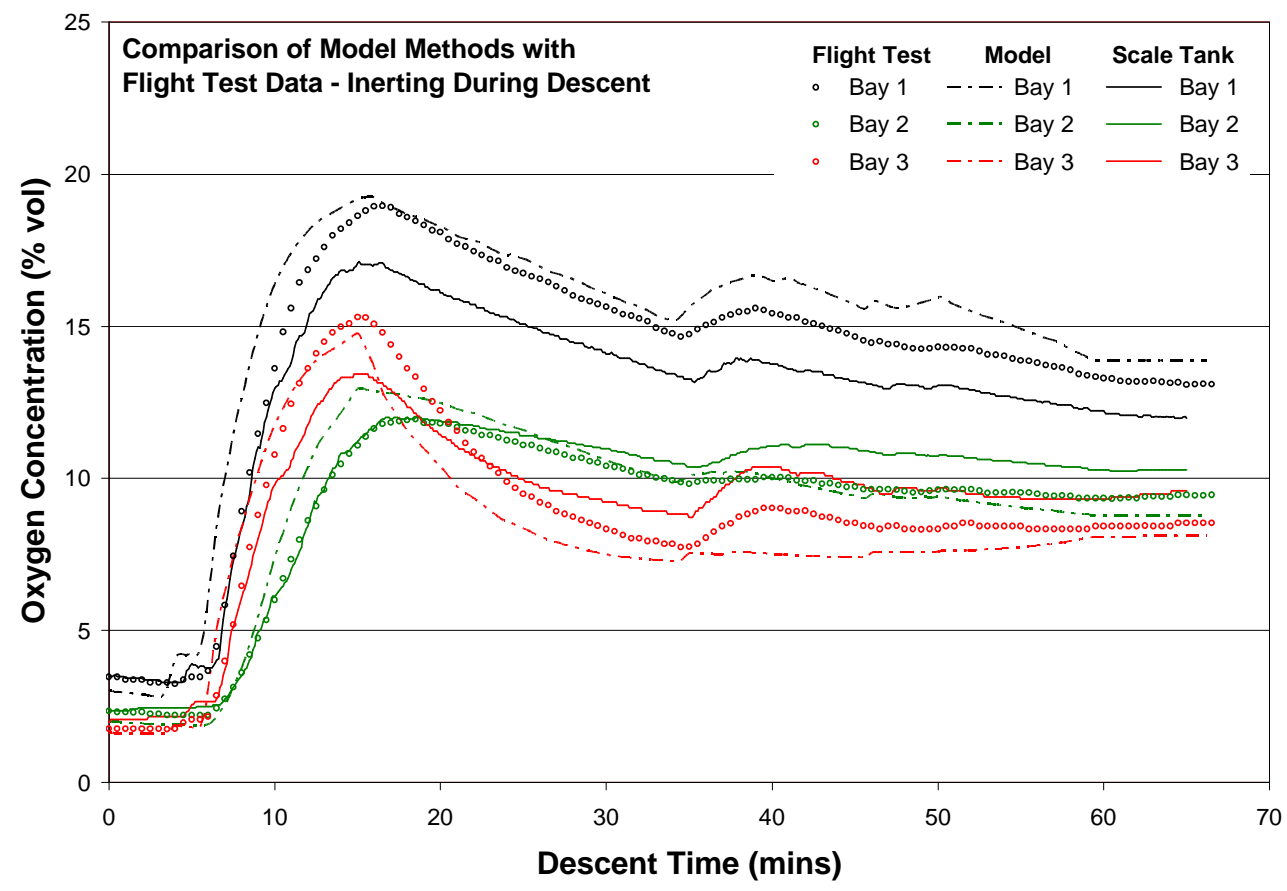

Figure 10. Comparison of bays 1, 2, and 3 oxygen concentration data for the analytical model and the scale plywood 747 CWT with the NASA 747 SCA data for the descent portion of a flight test.

Figure 12 illustrates the tank average oxygen concentration measured during the descent portion of the flight, which would also be used to design an inerting system for this fuel tank. Both the analytical model and the scale tank compare well with the calculated weighted average of the measured flight test data. 


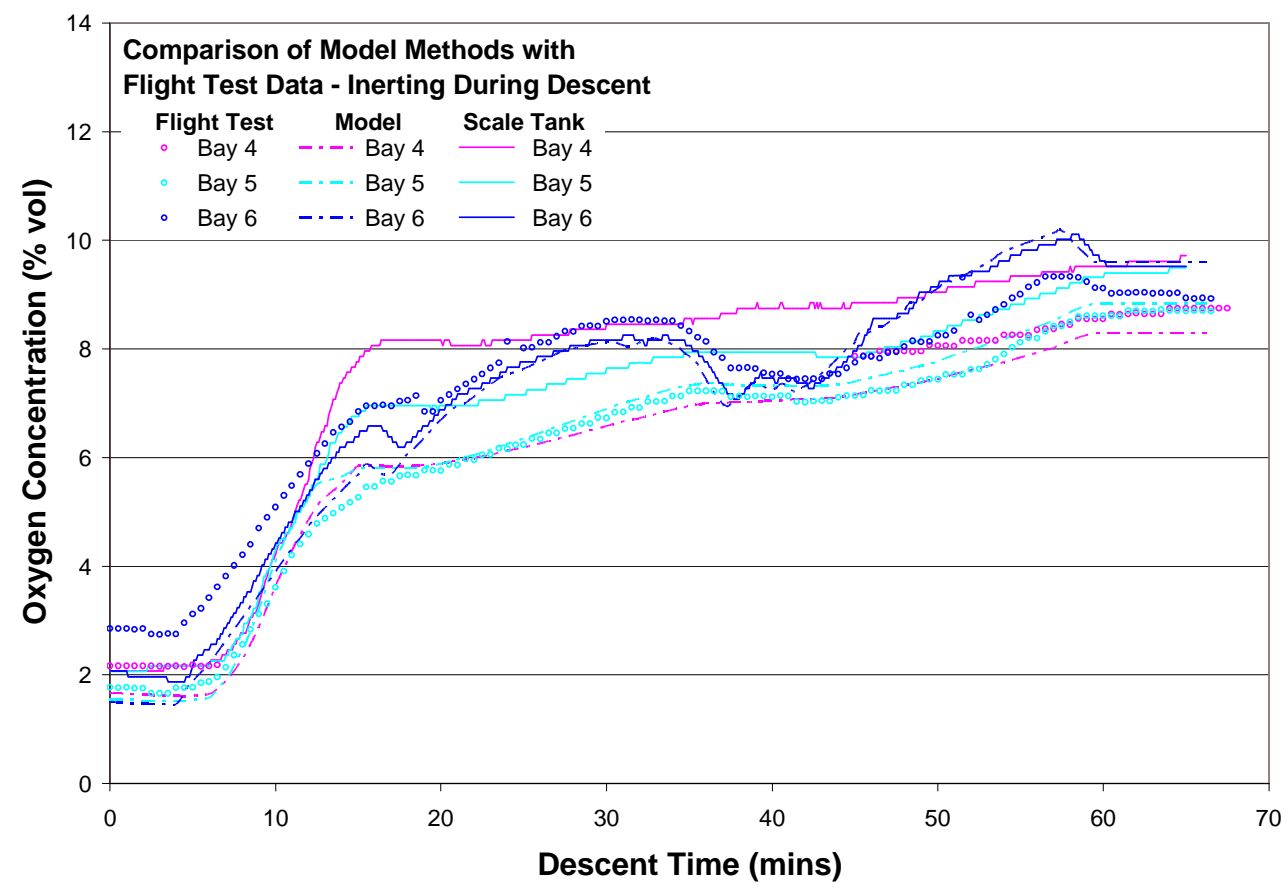

Figure 11. Comparison of bays 4,5 , and 6 oxygen concentration data for the analytical model and the scale plywood 747 CWT with the NASA 747 SCA data for the descent portion of a flight test.

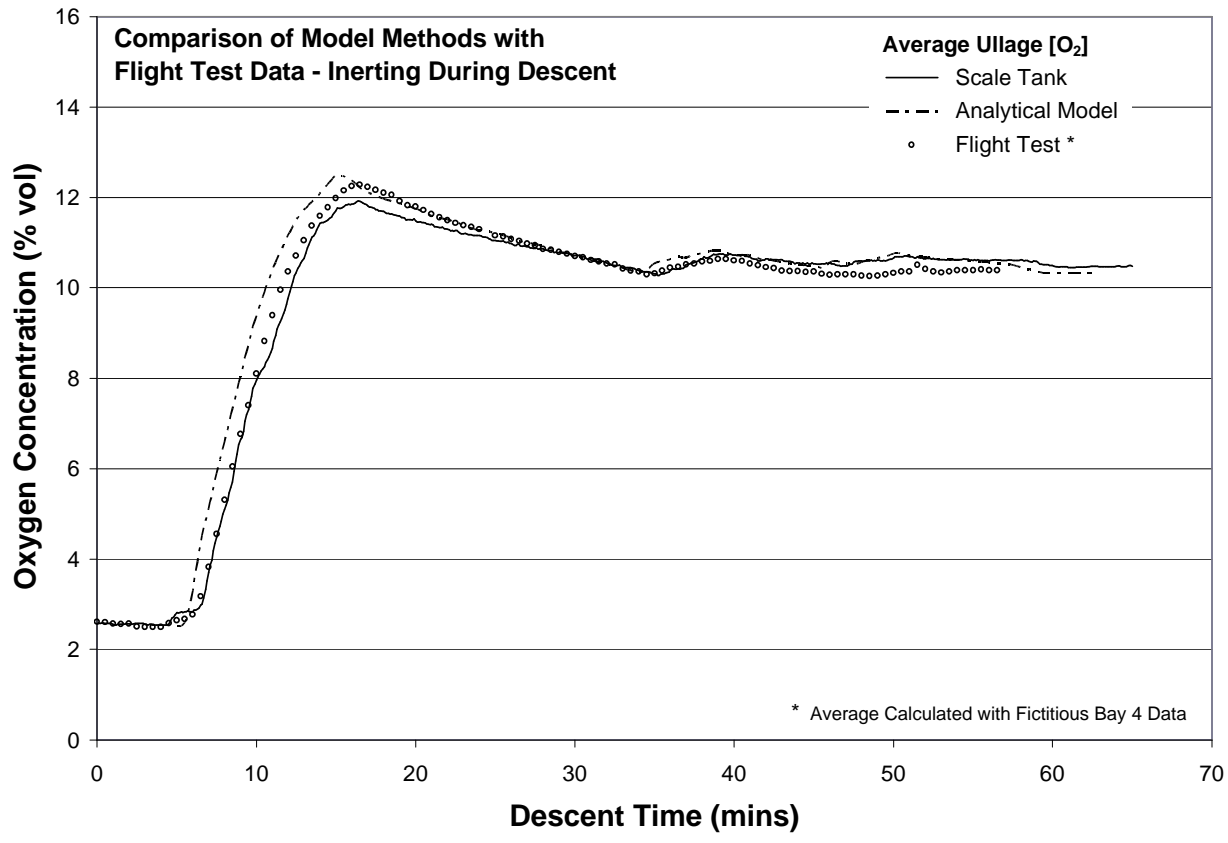

Figure 12. Comparison of average ullage oxygen concentration data for the analytical model and the scale plywood 747 CWT with the NASA 747 SCA data for the descent portion of a flight test.

To further evaluate both models, a different flight test descent was simulated and compared with the measured bay oxygen concentration distribution (figures 13 and 14). The flight profile of this descent was considerably different from the one previously discussed, which was similar to the flight profile of the test used to modify both models. Again, the trends of each bay oxygen concentration compare very well, with some large discrepancies between the magnitudes of the data. As was the case for the previously discussed test for bays 1,2, and 3, model results tended 
to bracket the flight test results with neither model method exhibiting significantly better agreement to the flight test data. The bay 1 analytical model results deviated from the flight test data by a maximum of 1.8 percent oxygen (13\% difference).

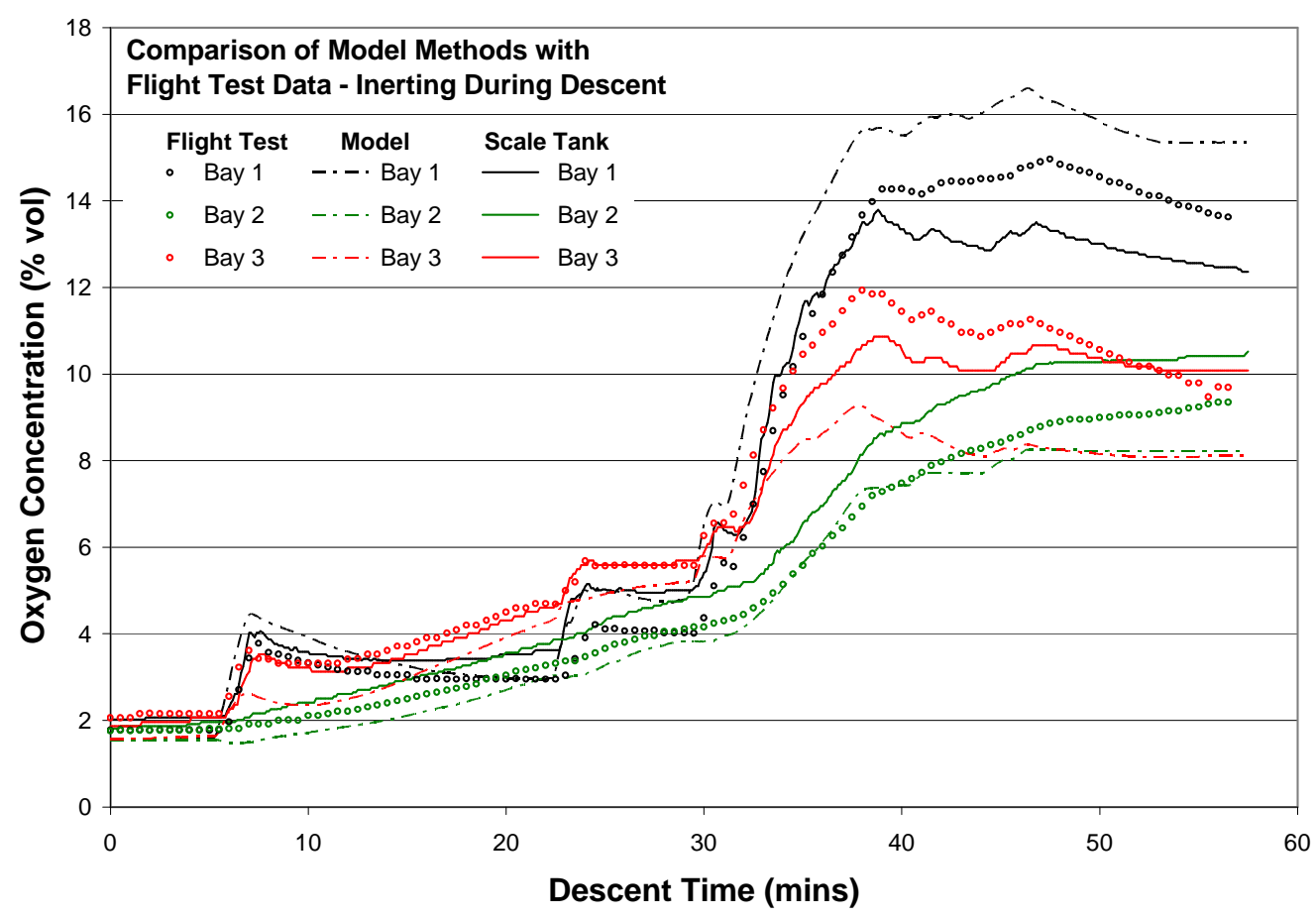

Figure 13. Comparison of bays 1, 2, and 3 oxygen concentration data for the analytical model and the scale plywood 747 CWT with the NASA 747 SCA data for the descent portion of a flight test.

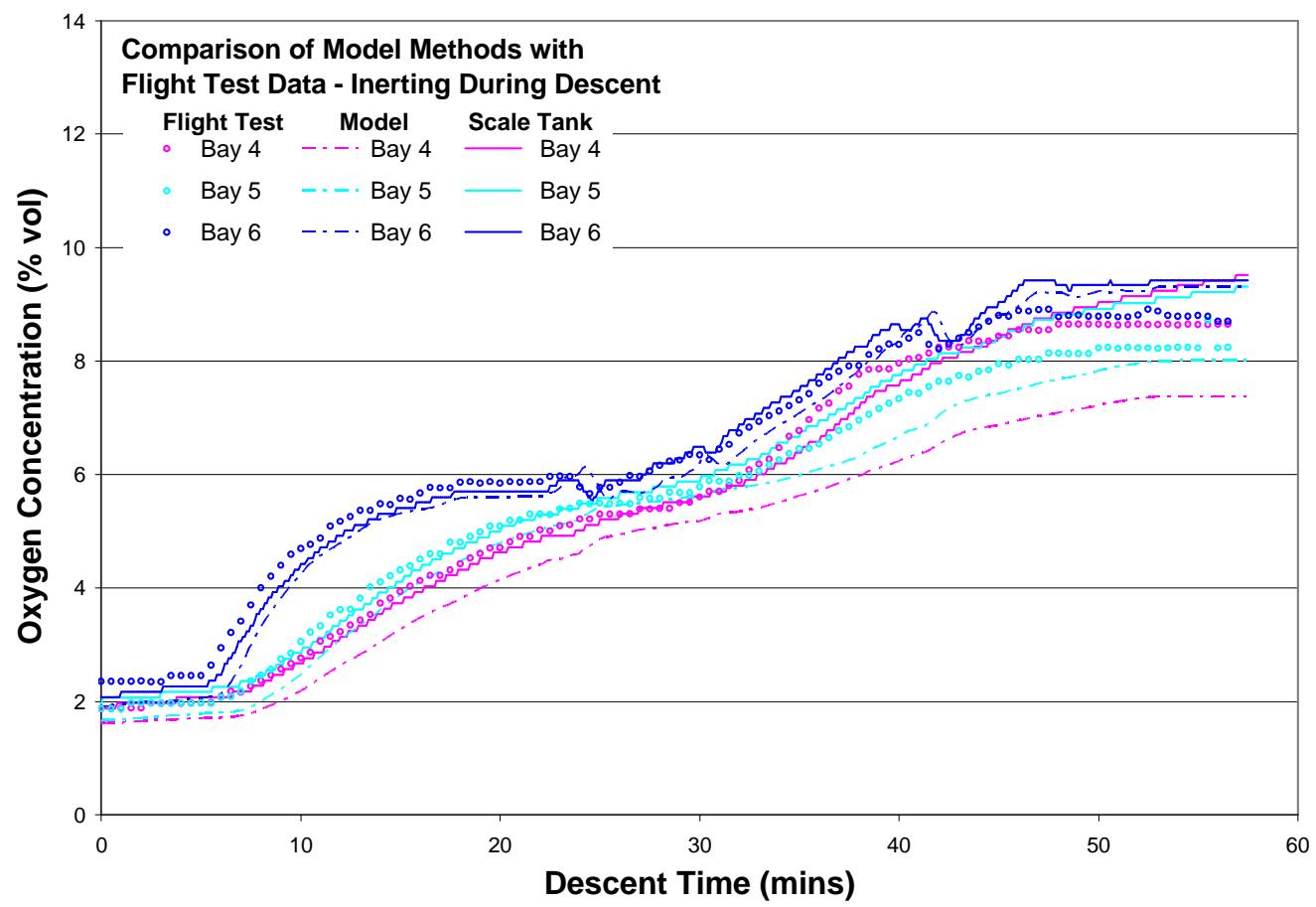

Figure 14. Comparison of bays 4,5 , and 6 oxygen concentration data for the analytical model and the scale plywood 747 CWT with the NASA 747 SCA data for the descent portion of a flight test. 
Figure 15 compares the average tank oxygen concentration calculated from both modeling methods with the average calculated from flight test data. As in the previous comparison of a flight test descent, the average ullage oxygen concentration for both model methods compared very well with the measured flight test data during the entire descent phase of the test.

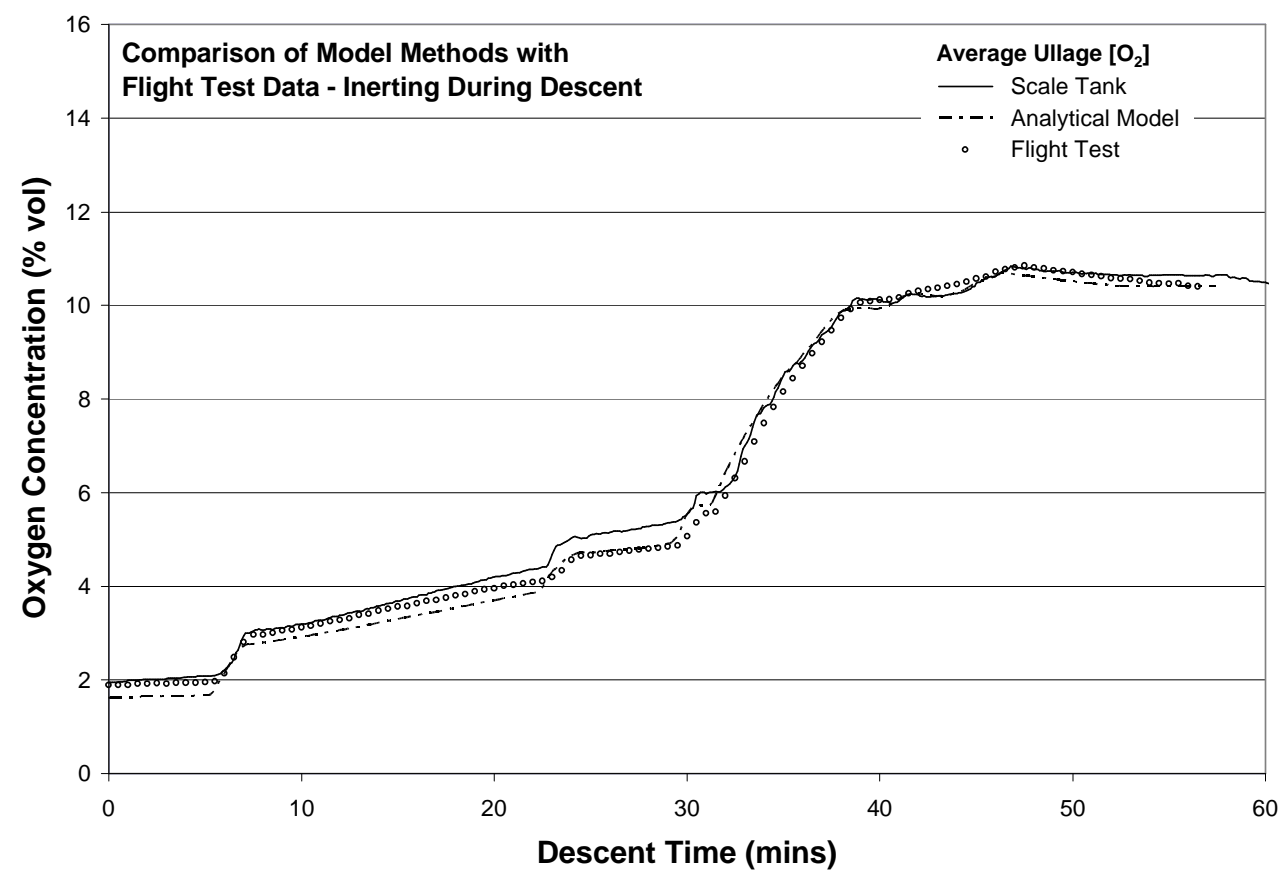

Figure 15. Comparison of average ullage oxygen concentration data for the analytical model and the scale plywood 747 CWT with the NASA 747 SCA data for the descent portion of a flight test.

It is noted that the analytical model better duplicated the oxygen concentration distribution from the measured flight test results from the first descent modeled in figures 10 and 11 than the second descent modeled in figures 13 and 14. The scale tank results, however, duplicated the measured flight test data equally well for both modeled descents, although not as well as the analytical model duplicated the descent in figure 10 . This is probably due to the similarity of the test in figure 10 and the test used to size the vent flow split in the analytical model. It illustrates that air entering the tank during the aircraft descent will probably not exhibit the behavior consistent with previous ground inerting calculations, which allowed for simple flow ratios to duplicate full-scale aircraft measurements during ground inerting events. Intuitively, air flow into the vent system is a more complex phenomenon and the amount of air entering bay 1 as opposed to bay 3 is probably a function of several changing parameters, such as descent rate and inert gas flow.

\section{Comparison of Flight Test Results with Computational Model}

To determine how effective more complex models can be at determining the inert gas distribution in a compartmentalized fuel tank being inerted during descent, a single flight test descent was simulated using the CFD software FLUENT. This single flight test was also used to compare both simple modeling methods discussed in the previous section. Figure 16 gives the comparison of the CFD model data with the measured flight test results. Although the modeling method is significantly more complex than the two FAA methods, the results are comparable in terms of the ability of the model to duplicate the peak and resulting oxygen concentration in each bay. The calculated resulting average ullage oxygen concentration was comparable compared to both the flight test results and the simple FAA modeling methods. 


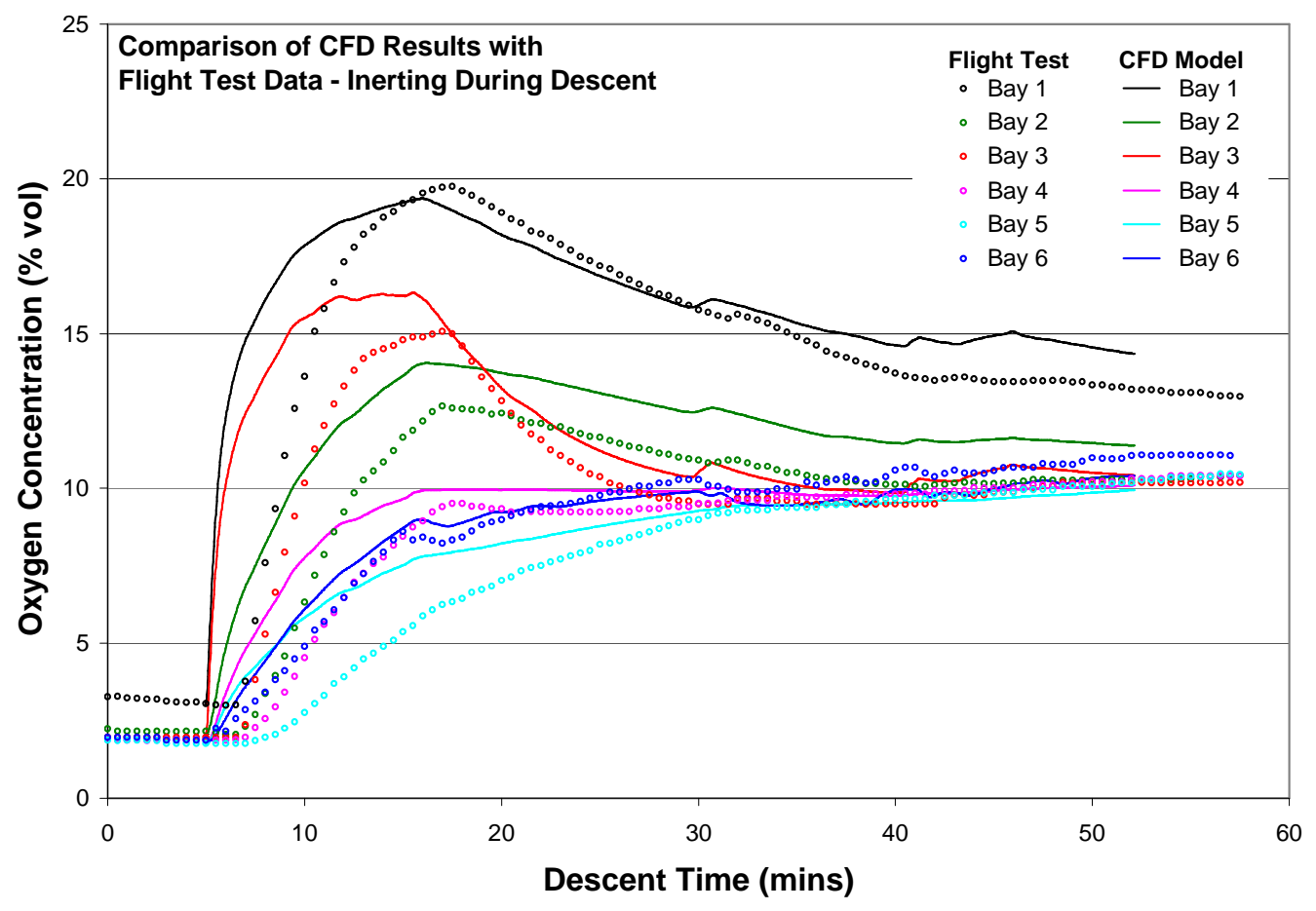

Figure 16. Comparison of bay oxygen concentration data for the computational FLUENT model with the NASA 747 SCA data for the descent portion of a flight test.

\section{Summary}

The FAA has developed analytical and physical models of the inert gas distribution in a compartmentalized fuel tank, in terms of ullage oxygen concentration, given a measured OBIGGS performance and a given flight cycle. Both the analytical model and the scale tank model methods gave a good prediction of the average ullage oxygen concentration measured during flight tests in a multiple-bay CWT with one deposit and two external vents. Both predicted bay oxygen concentration data trends were consistent with the measured flight test results, but deviated from the peak and resulting flight test oxygen concentration data. The largest deviations were observed for the critical bay 1 , which is the bay most important to designing the proper size inerting system for this fuel tank. These deviations were as high as 1.8 percent oxygen greater than the measured flight test results. Additional work is required to better understand the limitations of predicting the distribution of the oxygen concentration in compartmentalized, multiple-bay fuel tanks. The computational model demonstrated it could be an effective tool for validating and modifying simple models. More research is needed to determine how this more reliable, timeconsuming, and resource intensive method could be used to help design inerting systems and improve inert gas deposit methods.

\section{References}

${ }^{1}$ Seibold, D. W., "Development and Evaluation of an Airplane Fuel Tank Ullage Composition Model, Volume I-Airplane Fuel Tank Ullage Computer Model," Aero Propulsion Laboratory Report AFWAL-TR-87-2060, October 1987.

${ }^{2}$ Burns, Michael and Cavage, William M., "Inerting of a Vented Aircraft Fuel Tank Test Article With Nitrogen-Enriched Air,” FAA Report DOT/FAA/AR-01/6, April 2001.

${ }^{3}$ Cavage, William M. and Kils, Ole, "Inerting a Boeing 747SP Center Wing Tank Scale Model With Nitrogen-Enriched Air,” FAA Report DOT/FAA/AR-02/51, May 2002.

${ }^{4}$ Cavage, William M., "Modeling Inert Gas Distribution in Commercial Transport Aircraft Fuel Tanks," AIAA Conference Paper 2002-3032, September 2001.

${ }^{5}$ Cavage, William M., "Modeling of In-Flight Fuel Tank Inerting for FAA OBIGGS Research," Paper Submitted to the 4th Triannual Fire and Cabin Safety Research Conference, November 2004.

${ }^{6}$ Burns, Michael and Cavage, William M., "A Description and Analysis of the FAA Onboard Oxygen Analysis System," FAA Report DOT/FAA/AR-TN03/52, June 2003.

${ }^{7}$ Burns, Michael et. al., "Evaluation of Fuel Tank Flammability and the FAA Inerting System on the NASA 747 SCA," FAA Report DOT/FAA/AR-04/41, December 2004. 